\title{
Revising the Question of Keratoconus Classification
}

\author{
${ }^{1}$ Svetlana Izmaylova, ${ }^{2}$ Olga Komarova, ${ }^{3}$ Aleksandr Semykin, ${ }^{4}$ Maria Konovalova, ${ }^{5}$ Marina Zimina
}

\section{ABSTRACT}

Aim: To develop a new surgical keratectasia classification.

Materials and methods: We did analysis of existing variants of classification of keratectasia, discussion of newly appeared classifications. We discussed advantages and disadvantages of the presented information. We also discussed the decision of a question on creation of the optimum approach to surgical treatment of patients depending on a kind and a stage of keratectasia.

Results: Keratectasias were classified according to the presence of the ectatic process progression (progressive and stable); type of ectasia (primary and secondary); ectasia symmetry (symmetrical and nonsymmetrical); stages (0, I, II, III and IV). The following are recommended for each stage: Subclinical stage 0: Observation and check-up every 6 months; stage I: Ultraviolet (UV) cross-linking; stage II: Intracorneal ring segments (ICRS) implantation, UV cross-linking only if residual ametropia correction by photorefractive keratectomy (PRK) or toric intraocular lenses (TIOL) implantation is planned; stage III: Deep anterior lamellar keratoplasty (DALK); stage IV: penetrating keratoplasty (PK).

Conclusion: The presented keratectasia classification is based on modern diagnostic methods; it allows to determine the tactic of surgical treatment, depending on the type and stage of the pathological process.

Clinical significance: Our classification helps doctors to easily put the stage of keratoconus process and decide on the following surgical treatment.

Keywords: Cross-linking, Implantation of toric intraocular lenses, Intrastromal corneal ring segments, Keratoconus, Keratoconus classification, Keratoplasty.

How to cite this article: Izmaylova S, Komarova O, Semykin A, Konovalova M, Zimina M. Revising the Question of Keratoconus Classification. Int J Kerat Ect Cor Dis 2018;7(1):82-89.

Source of support: Nil

Conflict of interest: None

\section{INTRODUCTION}

Keratectasia is a progressive dystrophic corneal disease caused by a number of genetic and acquired factors. The disease is characterized by a progressive depletion,

\footnotetext{
${ }^{1}$ Head, ${ }^{2,5}$ Fellow, ${ }^{3}$ Senior Fellow, ${ }^{4}$ Resident

${ }^{1-5}$ Department of Transplantation and Eye Anterior Segment Reconstructive Surgery, S. Fyodorov Eye Microsurgery Federal State Institution of the Russian Ministry of Health, Moscow, Russia

Corresponding Author: Maria Konovalova, Resident Department of Transplantation and Eye Anterior Segment Reconstructive Surgery, S. Fyodorov Eye Microsurgery Federal State Institution of the Russian Ministry of Health, Moscow Russia, e-mail: mariakonovalova11@gmail.com
}

stretching and alteration in the curvature of the central and lower parts of the cornea; it acquires conical shape, the vertex shifts downward, irregular astigmatism develops, and visual functions significantly decrease..$^{1-3}$

The detectability of keratectasia is steadily growing. ${ }^{4}$ This phenomenon might be associated with many factors, including the emergence of modern methods of diagnosing keratectasia, which allows to reveal the disease at its earliest stage of development. The widespread use of excimer laser refractive interventions is as well one of the reasons for the increased number of iatrogenic keratectasia.

The pathogenesis of keratectatic process appearance has not been yet sufficiently studied. Researchers are inclined to believe that the main reason is genetically predisposed violation of collagen formation and its packaging in the stroma of the cornea, which leads to a disruption in the structure and architectonics of the cornea. Collagen fibrils lose their strict orientation and are located chaotically that leads to a destructive process. Clinically, this is manifested by progressive thinning, stretching, changes in the curvature of the central and lower parts of the cornea, and in the advanced stage by its significant scarring. ${ }^{5}$

Treatment of patients with keratectasia of various geneses should be comprehensive, taking into account the stage of the disease. Currently, there are the following methods of treating keratectasia:

- Biomechanical corneal remodeling (intrastromal keratoplasty) with implantation of one or two ICRS of different height and arc length. 6,7

- Biochemical corneal remodeling (UV cross-linking of corneal collagen). $., 8,9$

- Deep anterior lamellar and PK (for advanced stages of keratectasia).

However, nowadays, there is no consensus on the staging of keratoconus and the appropriate treatment plan for each stage.

Furthermore, important is the issue of further rehabilitation and the choice of the method for correcting residual ametropia in patients with stabilized keratectatic process. Depending on the age of patients, objective examination data, social activity, and occupation, the correction of residual ametropia can be performed by means of transepithelial PRK, implantation of phakic IOL, phacoemulsification with the implantation of pseudophakic TIOL.

The historical aspect of keratoconus classification concept development is of great interest. Over the years, 
Revising the Question of Keratoconus Classification

the most common among ophthalmologists was the classification of M Amsler, in which four stages of keratoconus were based on biomicroscopy, keratometry, visual acuity, and keratotopography.

At stage I, there is a "discharge" of the stroma, and there are slight changes in keratometric values. The value of minimum radius of curvature of the cornea is more than $7.2 \mathrm{~mm}$. Visual acuity is 0.1 to 0.5 and is amenable to correction by means of cylindrical glasses.

Stage II is characterized by the decrease of minimum radius value of corneal curvature to 7.19 to $7.1 \mathrm{~mm}$. Visual acuity is 0.1 to 0.4 and is also amenable to correction with glasses with cylindrical lenses, the manifestation of initial ectasia, and thinning of the cornea could be presented.

For stage III, there is a significant bulging of the cornea, as well as thinning. Visual acuity is in the range of 0.02 to 0.12 and is amenable to correction only by rigid gas-permeable lenses; often, patients do not tolerate this type of correction. The value of minimum radius of cornea curvature is 7.09 to $7.0 \mathrm{~mm}$, in addition to clouding of Bowman's layer.

In stage IV, there are stromal opacities and changes in Descemet's layer. Keratometry is usually not available. The visual acuity does not exceed 0.01 to 0.02 and cannot be corrected. The value of the minimum radius of corneal curvature is less than $6.9 \mathrm{~mm} .^{10,11}$

Subsequently, new classifications were developed. Rabinowitz $z^{5}$ combined stages I and II of keratoconus in a subclinical form, and III to IV in the clinical stage of the disease. Other researchers proposed to classify the keratoconus according to the radius of curvature of the cornea: Stage I (initial) with a radius of curvature $>6.80 \mathrm{~mm}$, stage II (pronounced) with a radius of 6.0 to $6.80 \mathrm{~mm}$, and stage III with a radius of curvature $<6.0 \mathrm{~mm} .^{12}$

Based on corneal topography analysis, several types of keratoconus are described according to the shape of corneal deformation: Peaked, tufted, pike-shaped, spherical, ellipsoidal, and atypical: Pike-shaped and low-peaked. In addition, three clinical forms of keratoconus have been identified: Dorme fruste keratoconus, abortive form and classical keratoconus as well as three forms of the disease progression: Not progressive, slowly progressing, and rapidly progressing. ${ }^{13,14}$

In order to select a rational method of treatment, surgical classifications are proposed: Presurgical, surgical, and terminal. ${ }^{15}$

These classifications are based on visual acuity, refraction, corneal thickness, radius of curvature, depth of anterior chamber, eye length, presence of corneal opacities, and the tolerability of contact lenses.

However, the Amsler-Krumeich classification is used more often in clinical practice; it is rather neat and simply reflects the main manifestations of the illness (Table 1).
Table 1: Classification of keratoconus by Amsler-Krumeich

\begin{tabular}{|c|c|}
\hline Stage I & $\begin{array}{l}\text { - The cone-shaped cornea } \\
\text { - The initial appearance of the Vogt lines } \\
\text { - Astigmatism }<5.0 \mathrm{D} \\
\text { - Keratometry } \leq 48.0 \mathrm{D} \\
\text { - Absence of corneal opacities } \\
\text { - A slight decrease in visual acuity }(0.5-1.0) \text { and the } \\
\text { possibility of correction with cylindrical glasses }\end{array}$ \\
\hline Stage II & $\begin{array}{l}\text { - There is a presence of Vogt lines } \\
\text { - Irregular astigmatism increases }(5.0-8.0 \mathrm{D}) \\
\text { - Keratometry } \leq 53.0 \mathrm{D} \\
\text { - The thickness of the cornea in the center is } \geq 400 \mu \mathrm{m} \\
\text { - Absence of corneal opacities } \\
\text { - Decreased visual acuity of } 0.1 \text { to } 0.4\end{array}$ \\
\hline Stage III & $\begin{array}{l}\text { - Bulging and thinning of the cornea } \\
\text { - Astigmatism increases to } 8.0 \text { to } 10.0 \mathrm{D} \\
\text { - Refraction of the cornea }>53.0 \mathrm{D} \\
\text { - The thickness of the cornea in the center is } 300 \text { to } \\
400 \mu \mathrm{m} \\
\text { - There are no opacities of the cornea } \\
\text { - Visual acuity is reduced to } 0.12\end{array}$ \\
\hline Stage IV & $\begin{array}{l}\text { - The degree of ectasia and thinning of the cornea } \\
\text { increases } \\
\text { - The thickness of the cornea in the center is }<200 \mu \mathrm{m} \\
\text { - Refraction of the cornea }>55.0 \mathrm{D} \\
\text { - The presence of central opacity of the cornea } \\
\text { - Visual acuity } 0.01 \text { to } 0.02 \text { (not corrected) clinical } \\
\text { refraction is not determined }\end{array}$ \\
\hline
\end{tabular}

It should be noted that generally keratoconus is diagnosed at its advanced stage. For early detection of keratoconus, in addition to traditional methods of investigation, it is necessary to carry out a whole complex of special diagnostic techniques. Therefore, a significant contribution to the early diagnosis of keratectasia has made the introduction of confocal microscopy in the clinical practice, which allows (in vivo) to establish the earliest manifestations of the disease at the cellular level. In addition, the pathological process that leads to an irregularity of the corneal surface and consequently to an increase in optical aberrations significantly reduces visual acuity. In addition, optical coherence tomography (OCT)-pachymetry makes it possible to determine the cornea thickness at all points, indicating the possible changes in its topography. ${ }^{3}$

\section{REVIEW RESULTS}

The analysis of the results of surgical treatment of more than 1,000 patients with progressive keratectasia of various geneses allowed us to systematize the obtained data and create a surgical classification that allows us to recommend a particular type of surgical intervention and determines a complex approach for treating keratoconus patients. We based our classification on the following criteria: Best corrected visual acuity (BCVA), biomicroscopy, Kmax, the minimal corneal thickness value, findings on 
confocal microscopy, and Pentacam HR (Oculus). We have chosen these criteria to estimate the condition of both corneal surfaces, the anterior and the posterior as accurately as possible. The examination involving modern diagnostic methods makes it possible to specify the method of surgical treatment for each particular patient.

We classify the keratectatic process as follows:

Subclinical form of keratoconus: Forme fruste (Fig. 1)

- $\quad \mathrm{BCVA} \geq 1.0$

- Biomicroscopy: No changes

- Kmax $\leq 45.0 \mathrm{D}$

- The minimum OCT-pachymetry value $\geq 500 \mu \mathrm{m}$

- Confocal microscopy: Without special features

- Pentacam HR: A pattern of a peninsula or an island on an elevation map

- Recommended: Dynamic control

\section{Stage I}

- BCVA 0.8 to 1.0 (Fig. 2)

- Biomicroscopy: A symptom of "fireworks"

- Kmax 45.0 to 48.0 D

- The minimum value of OCT-pachymetry is 475 to $500 \mu \mathrm{m}$

- Confocal microscopy: Pseudo-keratinization of the epithelium, areas of sparsity of the corneal stroma

- PentacamHR: Island pattern, front surface elevation of the cornea 8 to $25 \mu \mathrm{m}$, elevation of the posterior surface of the cornea 28 to $39 \mu \mathrm{m}$
- Recommended: UV cross-linking with subsequent (if necessary) correction of the initial ametropia by the PRK. In the presence of opacification in the native lens-phacoemulsification with the implantation of a pseudofacial TIOL.

\section{Stage II}

- $\quad$ BCVA 0.1 to 0.7 (Fig. 3)

- Biomicroscopy: Fleischner syndrome, Vogt's line, Monson's symptom, increase in depth and unevenness of the anterior chamber, thinning of the cornea biomicroscopically.

- Kmax: 48.0 to $65.0 \mathrm{D}$

- The minimum value of OCT-pachymetry is 390 to $475 \mu \mathrm{m}$

- Confocal microscopy: Pseudo-keratinization of the epithelium, areas of sparsity of the stroma, vertical orientation of the keratocytes, the appearance of vertical striae in the supraendothelial layers of the stroma, hyperactivation of the stromal nerves, pleomorphism and polymegethism of the endothelial cells

- PentacamHR: The island pattern, the elevation of the front surface of the cornea: 26 to $65 \mu \mathrm{m}$; the elevation of the posterior surface of the cornea: 40 to $89 \mu \mathrm{m}$.

- It is recommended in the first stage of keratoconus to carry out an intrastromal keratoplasty. Depending on the type of ectasia (Figs 4 and 5), in cases of asymmetric keratectasia, implantation of one ICRS

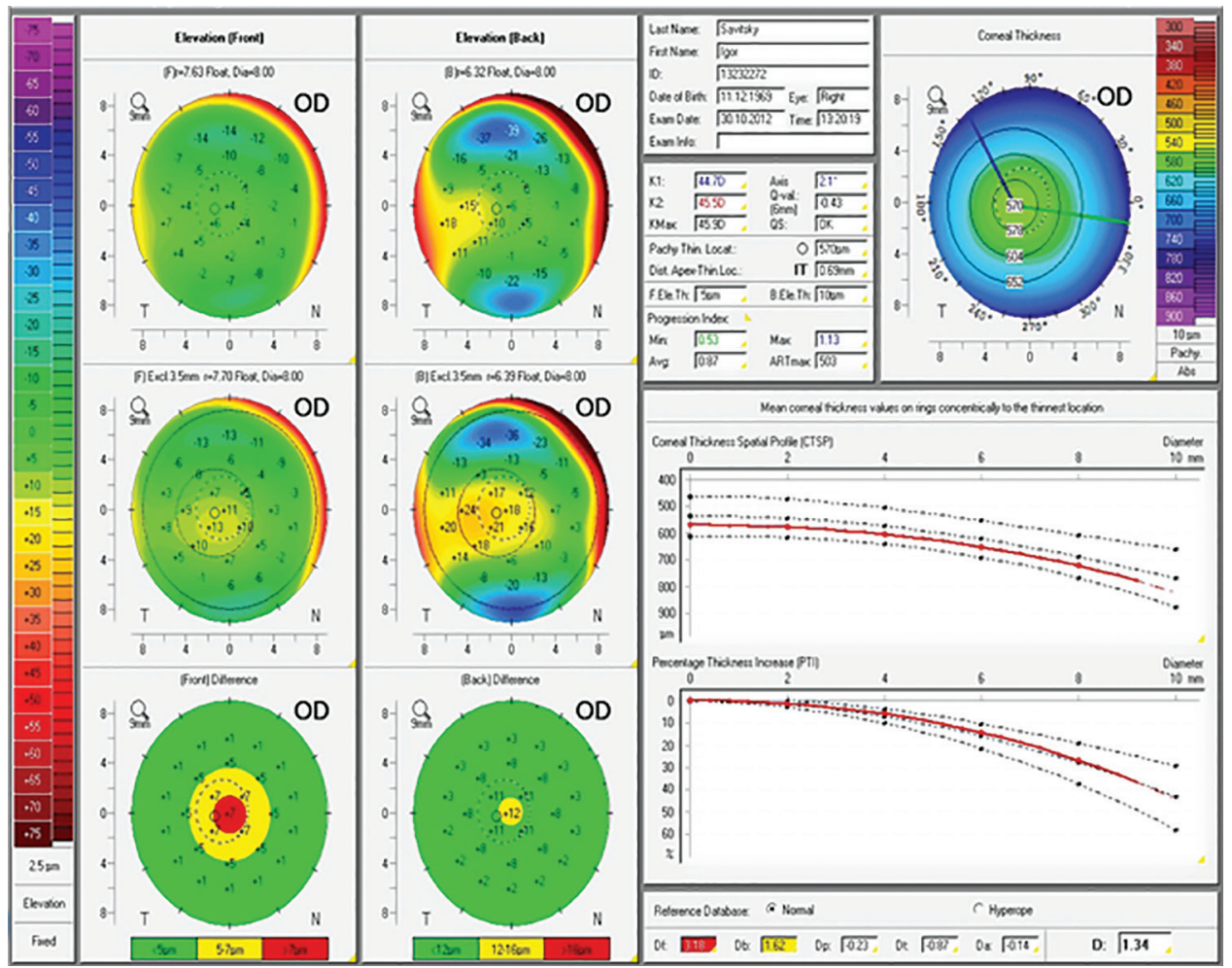

Fig. 1: Forme fruste. Kmax $\leq 45.0 \mathrm{D}$, minimal pachymetry $\geq 500 \mu \mathrm{m}$, a pattern of a peninsula or an island on an elevation map 


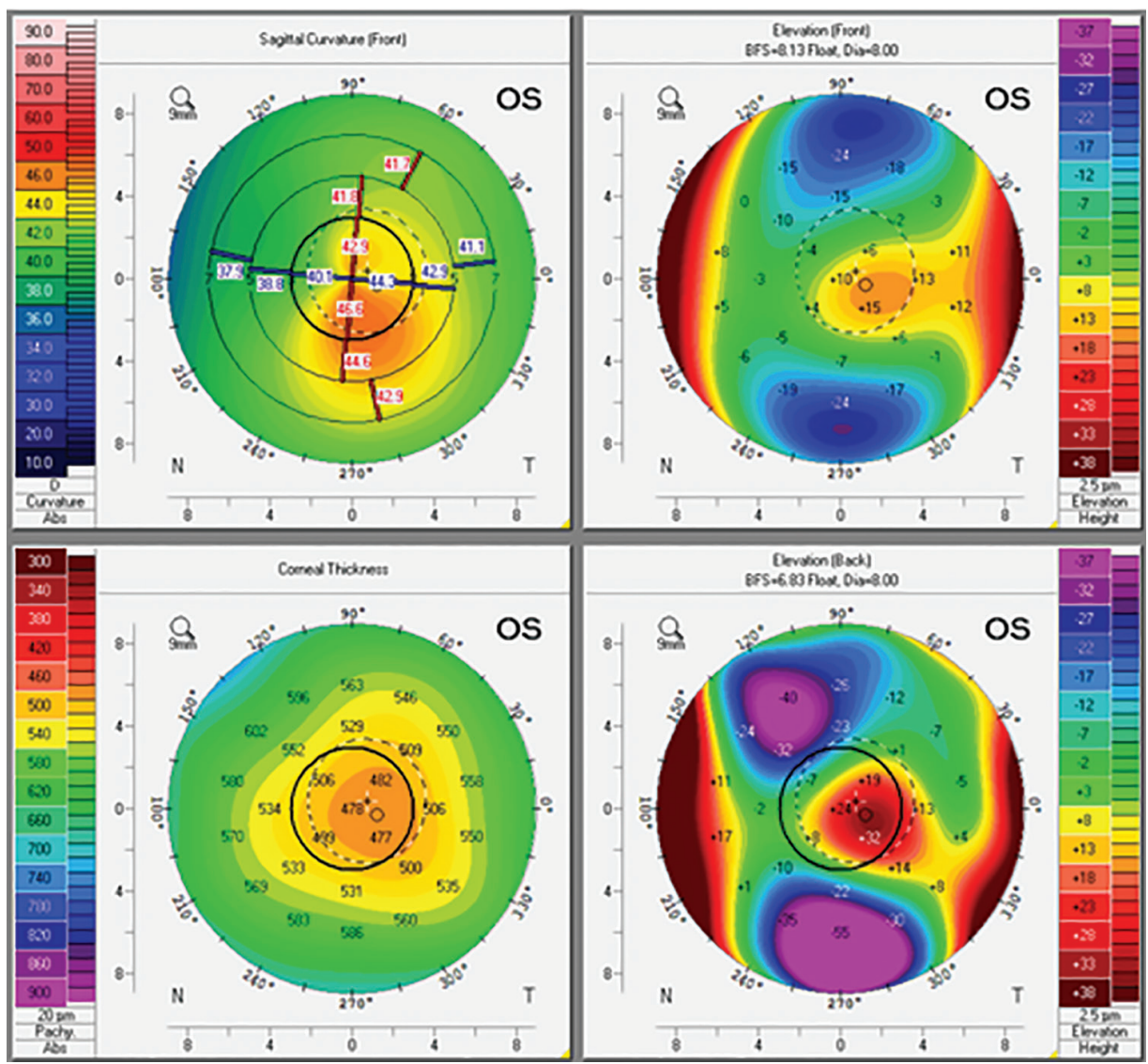

Fig. 2: Stage I. Kmax 45.0 to $48.0 \mathrm{D}$, minimal pachymetry is 475 to $500 \mu \mathrm{m}$, island-shaped pattern, anterior elevation 8 to $25 \mu \mathrm{m}$, posterior elevation 28 to $39 \mu \mathrm{m}$
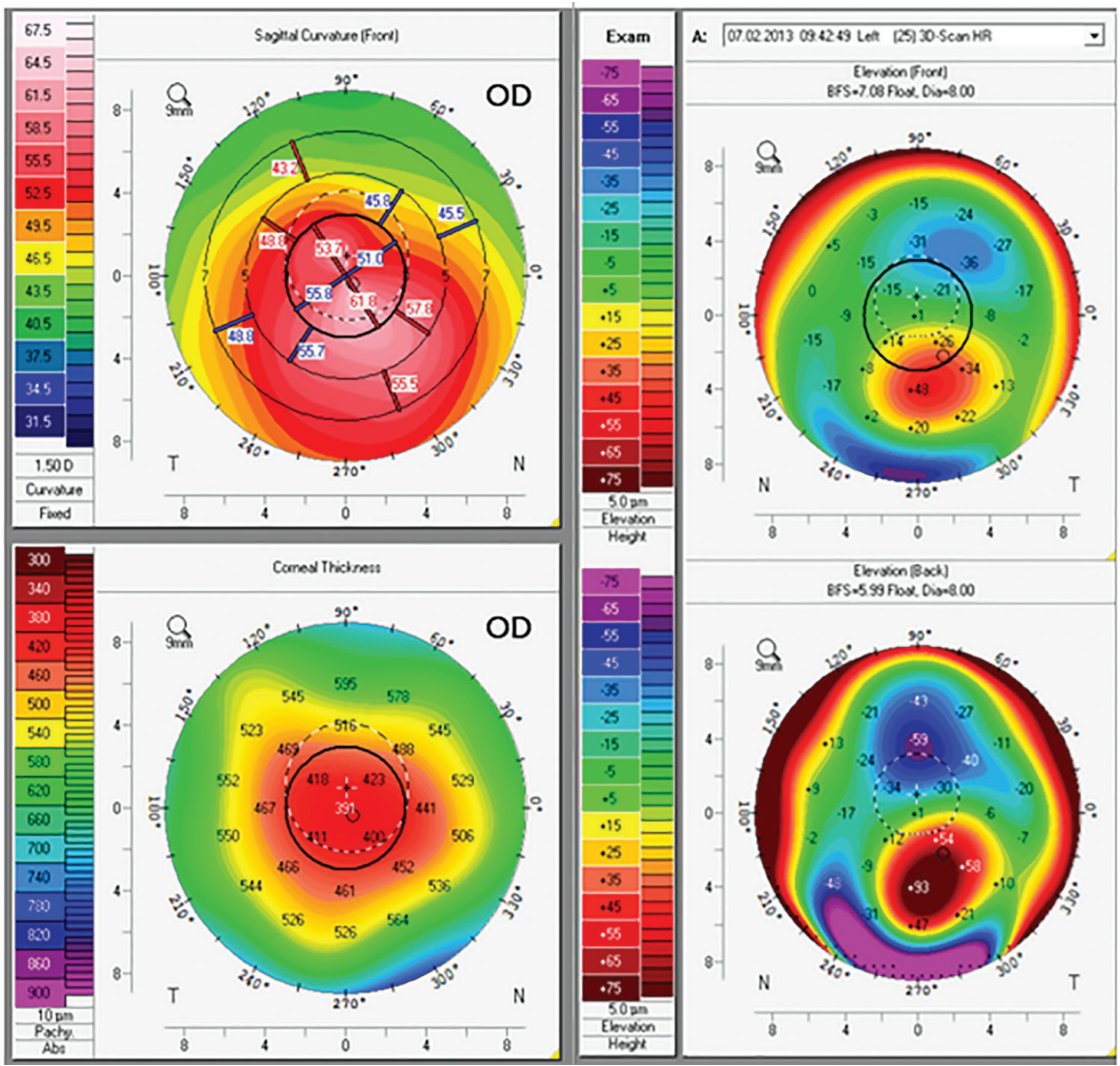

Fig. 3: Stage II. Kmax 48.0 to $65.0 \mathrm{D}$, minimal pachymetry is 390 to $475 \mu \mathrm{m}$, islandshaped pattern, anterior elevation 26 to $65 \mu \mathrm{m}$, posterior elevation 40 to $89 \mu \mathrm{m}$ 

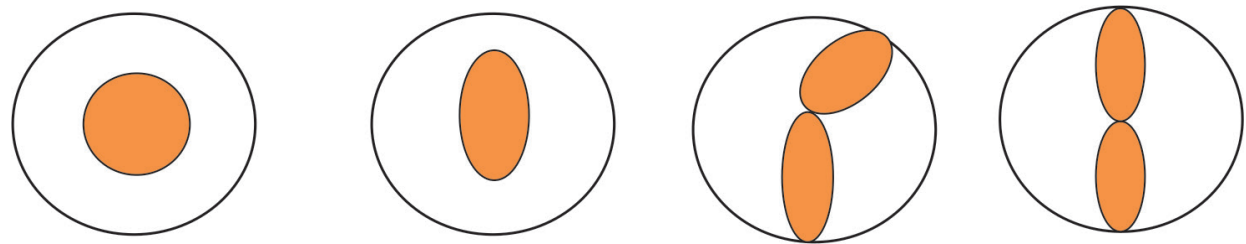

Fig. 4: Keratotopographic patterns of symmetric keratectasia
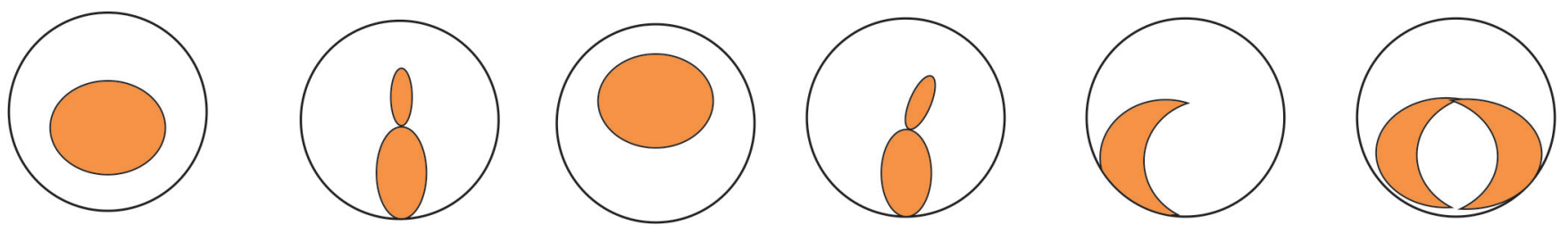

Fig. 5: Keratotopographic patterns of asymmetric keratectasia

into the most ecstatic area, in cases of symmetric keratectasia, implantation of two ICRS symmetrical along the steep axis. The UV cross-linking procedure is performed as an intermediate step. If further correction of residual ametropies is necessary, it could be performed with the help of PRK in a transparent natural lens or phacoemulsification with the implantation of a pseudophakic TIOL in case of lens opacity of varying severity, including myopic phacosclerosis.

\section{Stage III}

- $\quad$ BCVA 0.01 to 0.2 (Fig. 6)

- Biomicroscopy: The intensification of the symptoms of stage II in the absence of corneal opacities caused by a violation of the integrity of the Descemet's membrane

- Kmax: 65.0 to $75.0 \mathrm{D}$

- The minimum value of OCT-pachymetry is $\leq 390 \mu \mathrm{m}$

- Confocal microscopy: Increase in the number and strengthening of pronounced folding in the middle

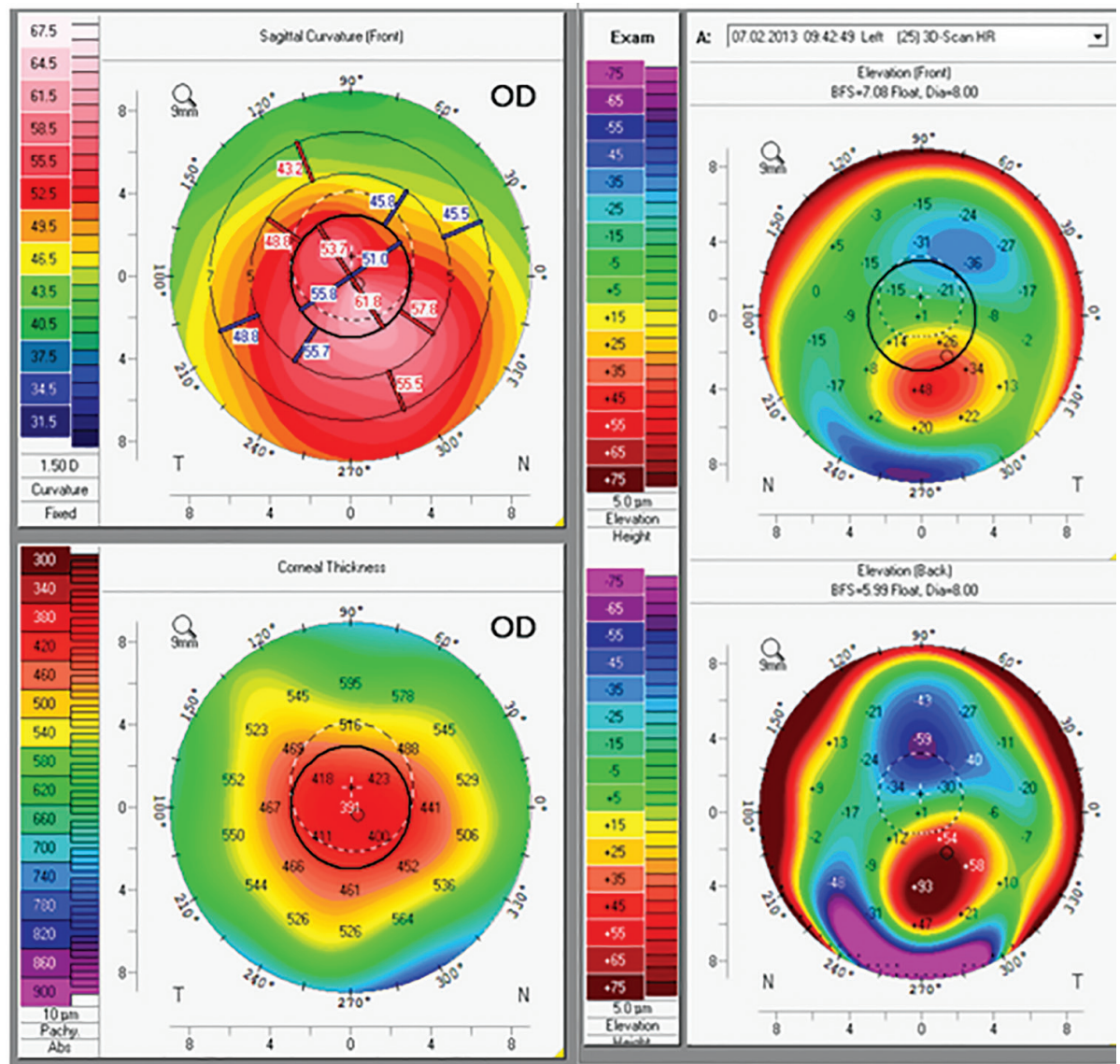

Fig. 6: Stage III. Kmax 65.0 to $75.0 \mathrm{D}$, minimal pachymetry is $\leq 390 \mu \mathrm{m}$, island-shaped pattern, front corneal elevation $\geq 65 \mu \mathrm{m}$, back corneal elevation $\geq 90 \mu \mathrm{m}$ 


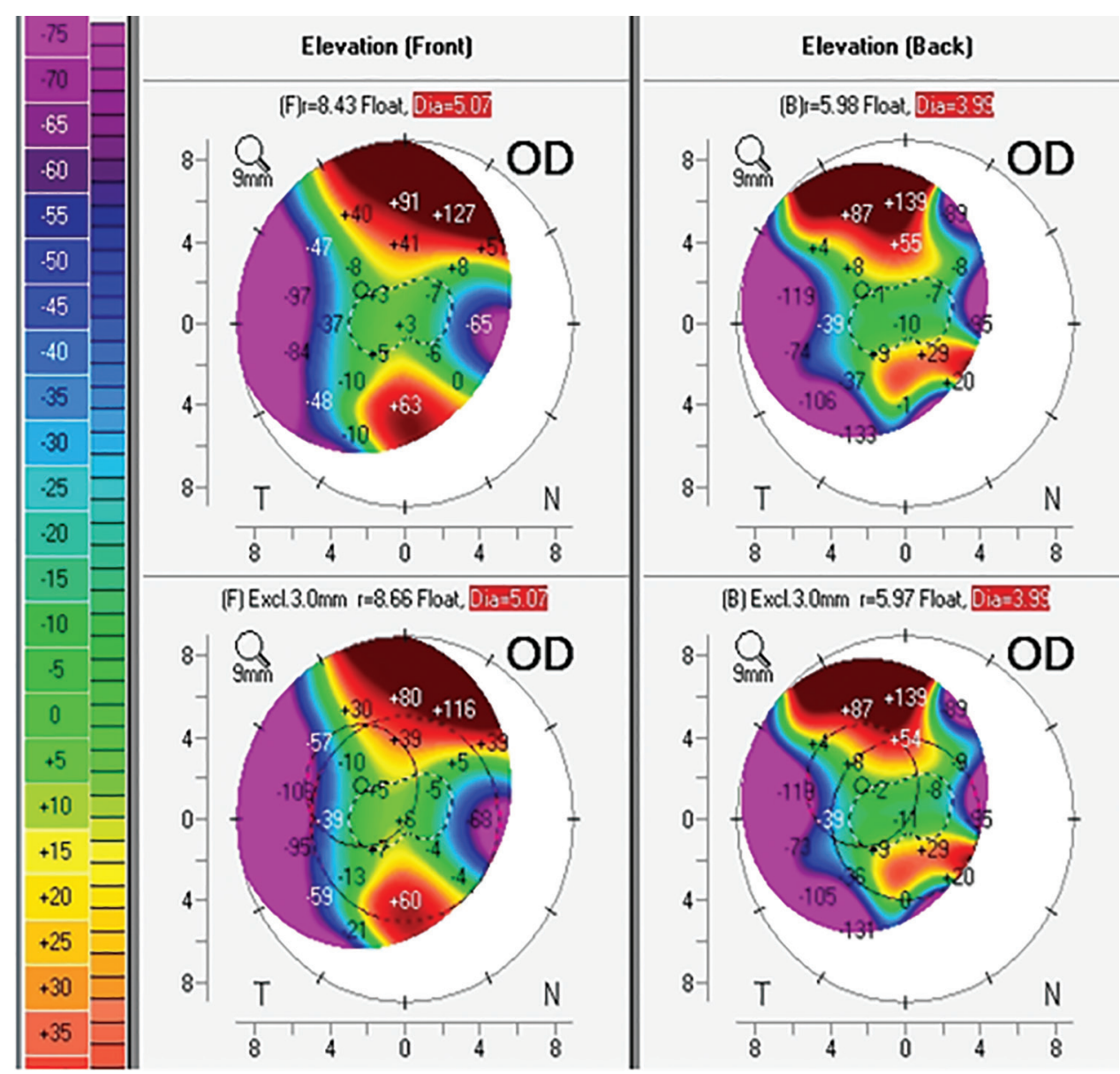

Fig. 7: Stage IV. Kmax $\geq 75.0 \mathrm{D}$, minimal pachymetry is 200 to $800 \mu \mathrm{m}$ (in acute stage), PentacamHR - unreliable data

and deep layers of the corneal stroma, the appearance of zones of stromal cellularity, endothelial cells density $\geq 1800$ cells $/ \mathrm{mm}^{2}$.

- PentacamHR: Island pattern, elevation of the front surface of the cornea $\geq 65 \mu \mathrm{m}$, elevation of the posterior surface of the cornea $\geq 90 \mu \mathrm{m}$

- It is recommended conducting anterior deep lamellar keratoplasty.

\section{Stage IV}

- BCVA $\leq 0.01$ (Fig. 7)

- Biomicroscopy: A violation of the transparency of the cornea, an increase in the depth and irregularity of the anterior chamber, a sharp manifestation pathognomonic for keratoconus symptoms, cicatricial changes in the Descemet's membrane

- $K \max \geq 75.0 \mathrm{D}$

- The minimum value of OCT-pachymetry is $200 \mu \mathrm{m}$

- Confocal microscopy: Cicatricial changes in the corneal stroma, endothelial cells density $\leq 1800$ cells / $\mathrm{mm}^{2}$ or not determined

- PentacamHR: The data are unreliable

- Recommended: PK
It should be clarified that the division of the pathological processes presented in this classification refers only to keratoconus as the only variant of keratectasia that is usually divided into stages.

\section{DISCUSSION}

Based on the analysis of our own results, we developed a surgical classification of keratectasia with an emphasis on the stage of keratoconus (Table 2). This classification takes into account not only traditional data (visual acuity, biomicroscopy), but also special modern diagnostic methods (OCT-pachymetry, computer keratotopography, confocal scanning microscopy of the cornea, corneal topography) using a rotating Scheimpflug camera Pentacam HR since they can detect the early stage of the disease and expose the signs of a process that indicates its progression. At the same time, depending on the set of initial signs of the pathological process at each stage of the disease, this classification provides recommendations that refer ophthalmologist to a certain algorithm of actions based on an adequate choice of the surgical treatment method. This is especially true in cases when, for the same stage of the disease, for example, stage III of the keratoconus, determined according to the generally accepted Amsler-Krumeich classification, it is 
Table 2: Izmaylova surgical classification of keratoconus

I. By the presence of
progression of keratectasia
II. By type of ectasia

III. By the type of ectasia (in accordance with the indicators of OCT-pachymetry, keratotopography, and analysis of elevation maps on the scanning topographer Pentacam HR)

IV. By stage (applies only to keratoconus)
- Progressing

- Stable

- Primary (keratoconus, keratoglobus, pellucid marginal degeneration)

- Secondary (posttraumatic, iatrogenic after refractive surgery (LASIK, PRK, keratotomy), and after penetrating and lamellar keratoplasty)

- Symmetric

- Asymmetric
- Subclinical form of keratoconus: Forme fruste

- Stage I

- Stage II

- Stage III

- Stage IV

possible to perform surgical procedures, such as implantation of ICRS, DALK, or PK. At the same time, the surgical classification developed by us clearly defines the criteria for choosing the method of surgery.

\section{CONCLUSION}

The expediency of developing a surgical classification is determined by the fact that despite the great variety of existing classifications, all of them, having a descriptive character, are based on standard survey methods that do not reflect modern concepts of the numerous

pathognomonic signs of this pathology, which, in our point of view, does not meet today's requirements. At the same time, none of them serves as a basis for choosing the tactics of surgery, which is currently a priority method of treating keratectasia of various geneses. Thus, a coherent system of complex stage treatment of patients with progressive keratectasia of various geneses was created based on obtained results, and based on a variety of technological developments, experimental studies, and modern diagnostic methods. We considered it expedient to develop a surgical classification that allows not only to determine the different stages of keratectasia based on modern methods of diagnosing but also to guide the practical doctor to an adequate algorithm of actions strictly defined by the patient's initial condition and a set of surgical technologies and approaches optimized by us.

\section{CLINICAL SIGNIFICANCE}

Consequently, proposed classification unlike the others is based on modern methods of diagnosing and surgical treating of keratectactic process. This classification takes into account the complexity of features inherent in various stages of the disease. It offers a possibility to identify the disease at its early stage and determine the optimal tactic for its surgical treatment using up-to-date surgical techniques depending on the type and stage of the pathological process, if necessary, correct the residual ametropia for further rehabilitation of the patients (Flow Chart 1). We have created the algorithm for the surgical treatment of keratectasia wishing to achieve maximum utility for clinicians of the classification we proposed.

Flow Chart 1: Surgical treatment algorithm in patients with different keratoconus stages

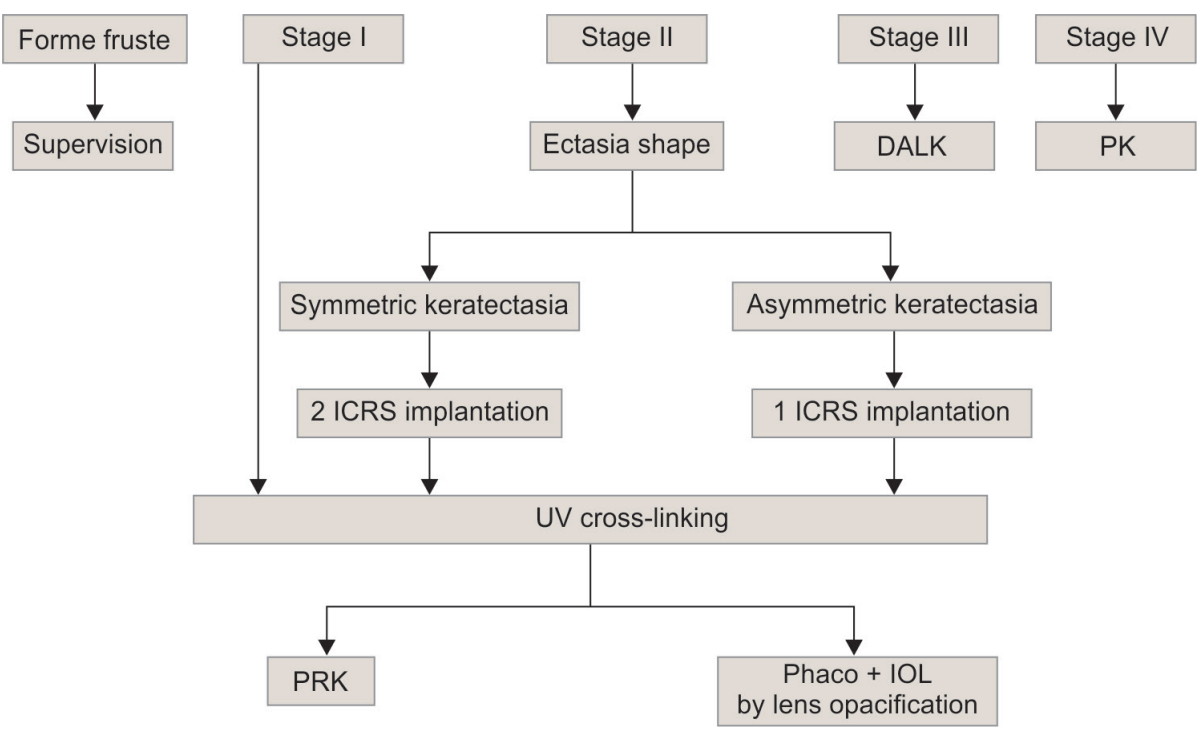




\section{REFERENCES}

1. Abugova T. Contact lenses and keratoplasty for keratoconus. Eye 1999; p. 1.

2. Kopaeva, VG. Modern aspects of through to-talk eratoplasty. Diss. PhD // M., Sciences, Moscow; 1982. p. 435.

3. Puchkovskaya, Z.; Titarenko, N. Keratoconus. Kishinev: Timlul; 1990.

4. Sevostyanov E, Gorskova E. Keratoconus plus. 2006.

5. Rabinowitz YS. Definition, etiology and diagnosis of keratoconus. Highlights Ophthalmol 2004;21:241-260.

6. Izmaylova S. Medical-technological system of surgical treatment of progressive ectasia of various genesis. 2014 . p. 201.

7. Malyugin B, Izmaylova S, Merzlov D, Pronkina S, Poruchikova $\mathrm{E}$, Semykin A. Long-term results of using various UV-crosslinking technologies in patients with progressive keratoconus. Ophthalmosurgery 2014;4:42-49.

8. Malyugin B, Izmaylova S, Avramenko S, Merzlov D. Treatment of paracentral keratectasias of various genesis by the method of intrastromal keratoplasty with implantation of the corneal semi-ring into the zone of highectasia. Ophthalmosurgery 2011;4:16-22.

9. Hafezi F, Kanellopoulos J, Wiltfang R, Seiler T. Corneal collagen crosslinking with riboflavin and ultraviolet $\mathrm{A}$ to treat induced keratectasia after LASIK. J Cataract Refract Surg 2007;33(12):2035-2040.

10. Amsler M. Frühdiagnose und Mikrosymptome. Ophthalmologica 1965;149:438-446.

11. Amsler M. Keratoconus. Bull De Sos. Beige d'ophthalm 1961;129:331-336.

12. Wilson, MS.; Millis, EA. Contact lenses in ophthalmology. Belfast: Butterworths and Co. Ltd., 1998

13. Abugova, TD. Early diagnosis and medical rehabilitation of patients with keratoconus by means of contact correction. Synopsis of thesis ... cand. med. Sciences. M. 1986. p. 17.

14. Kivaev, AA.; Shapiro, EI. ontact vision correction. Moscow: Medicine; 2000.

15. Slonimsky, YU.; Gerasimov, AS. Refractive penetrating keratoplasty. Moscow: Novella; 1992. 